\title{
ÉPOCA DE SEMEADURA, REGIMES DE CORTE, PRODUÇÃO E QUALIDADE DE SEMENTES DE MILHETO ${ }^{1}$
}

\author{
ROGÉRIO DEANDRADE COIMBRA², JOÃO NAKAGAWA ${ }^{3}$
}

\begin{abstract}
RESUMO - O milheto é uma gramínea anual, de clima tropical, empregada na alimentação animal como forrageira, em pastejo direto, para corte, feno, silagem e colheita de grãos para ração. $\mathrm{O}$ presente trabalho teve o objetivo de estudar o comportamento do milheto, após diferentes regimes de corte, semeado em duas épocas, para verificar a possibilidade de cultivá-lo em condições de Botucatu, 815 metros de altitude, 22 50 '59"S e 48 $25^{\prime} 54^{\prime \prime} \mathrm{O}$, visando a produção de sementes, como cultura em sucessão/rotação com outra de cultivo das águas. $\mathrm{O}$ experimento foi conduzido em vaso, sob túnel plástico, em delineamento de blocos ao acaso, com duas épocas de semeadura (abril e setembro), cada uma com cinco tratamentos: $\mathrm{T}_{1}$ ) crescimento livre, sem cortes; $\mathrm{T}_{2}$ ) um corte quando a planta atingiu 50 a $70 \mathrm{~cm}$ de altura; $\mathrm{T}_{3}$ ) um corte quando a planta atingiu o florescimento; $\mathrm{T}_{4}$ ) seqüência de três cortes quando a planta atingiu $50 \mathrm{a} 70 \mathrm{~cm}$ de altura; $\mathrm{T}_{5}$ ) seqüência de dois cortes quando a planta atingiu o florescimento, e cinco repetições. Foram avaliados a produção de sementes, os componentes de produção de sementes por planta, e a qualidade física e fisiológica das sementes. Os dados foram submetidos à análise estatística através da análise conjunta das épocas de semeadura e as médias comparadas pelo teste de Tukey a 5\% de significância. Os resultados apontam que a época de semeadura e o regime de corte afetam a produção e a qualidade das sementes de milheto. A semeadura em abril com no máximo um corte na fase vegetativa mostrou ser a melhor combinação para a produção de sementes de milheto em Botucatu.
\end{abstract}

Temos para indexação: Pennisetum americanum, manejo de corte, germinação, vigor.

\section{SOWING TIME, CUTTING SYSTEM, PRODUCTIONAND QUALITY OF PEARL MILLET SEEDS}

\begin{abstract}
Pearl millet is a tropical annual grass, used for animal feeding as forage, in direct pasture, for cutting, hay, silage and grain crop for ration. The objective of the present study was the investigation of the behavior of millet, after different cutting systems, sown at two times, to verify the possibility of cultivation under the conditions in Botucatu-SP, 815 meters altitude, $22^{\circ} 50^{\prime} 59^{\prime \prime} \mathrm{S}$ e $48^{\circ} 25^{\prime} 54^{\prime \prime} \mathrm{W}$, for seed production, as a crop in succession/rotation with another wet season crop. The experiment was carried out in pots, under a plastic tunnel, in a complete randomized block design, with two sowing times (April and September), each one with five treatments: T1) free growth, without cutting; T2) a cut when the plant reached 50 to $70 \mathrm{~cm}$ height; T3) cutting when the plant reached flowering; T4) sequence of three cuttings when the plant reached 50 to $70 \mathrm{~cm}$ height; T5) sequence of two cuttings when the plant reached flowering, and five replications. The variables evaluated were seed production, the component seed production per plant and the physical and physiological quality of the seeds. The data were submitted to the joint analysis of the sowing times and the averages were compared by the Tukey test at 5\% significance. The results showed that sowing time and the cutting system affected the millet seed production and the quality. Sowing in April with at most one cutting in the vegetative phase was shown to be the best combination for the production of pearl millet seeds in Botucatu.
\end{abstract}

Index terms: Pennisetum americanum, cut system, germination, vigor.

\footnotetext{
${ }^{1}$ Submetido em 08/12/2005. Aceito para publicação em 01/06/2006;

${ }^{2}$ Aluno do Programa de Pós-Gradução em Agronomia, área de concentração Agricultura, Faculdade de Ciências Agronômica, Universidade Estadual Paulista, Departamento de Produção Vegetal, Caixa Postal 237, CEP:
}

18603-790, Botucatu - SP, racoimbra@fca.unesp.br;

${ }^{3}$ Professor Titular Aposentado Voluntário, Departamento de Produção Vegetal,secdamv@fca.unesp.br. 


\section{INTRODUÇÃO}

O milheto (Pennisetum glaucum (L.) R. Br., P. americanum (L.) Leeke ou P. typhoides (Burm F.) J. Stapf \& C. E. Hubb) é uma planta anual de clima tropical, da família das gramíneas, com ciclo de aproximadamente 130 dias. Possui crescimento ereto e porte alto, podendo atingir 4 ou 5 metros de altura, sendo também conhecido como pasto italiano na região sul do Brasil (Salton e Kichel, 1997). É originário, provavelmente, das savanas africanas, apresentando capacidade de produzir sementes em condições extremamente secas e em solos de baixa fertilidade, porém respondendo bem às adubações.

Devido as suas características agronômicas de alta resistência à seca, ampla adaptação e boa produção de massa, aliado ao crescimento rápido, a espécie merece grande destaque em áreas de plantio direto no Brasil central, tanto na semeadura de outono-inverno quanto na primavera (Salton, 2001), com bons resultados para a soja cultivada em sucessão (Pereira, 1990; Silva, 1998; Lemos et al., 2003; Farinelli et al., 2004). Sua procura tem sido grande nos estados de Mato Grosso, Mato Grosso do Sul, Goiás, Bahia, Minas Gerais, São Paulo e Paraná (Netto et al., 1997); como opção de cultivo de inverno, em regiões de cerrado como Mato Grosso e Mato Grosso do Sul, ocupando áreas de 600.000 e 200.000ha, respectivamente (Salton, 2001).

Apesar de apresentar ampla capacidade de adaptação, melhor conhecimento das características da planta de milheto é fator importante para a expansão e aproveitamento correto da cultura, pois seu comportamento pode variar em função das diferentes condições ambientais. A época de semeadura do milheto varia de região para região, podendo, em locais tropicais, ser semeado continuamente (Alcântara e Bufarah, 1988).

Assim, para verificar as possibilidades de adaptação da cultura em uma região, onde as condições climáticas variam no decorrer do ano, há a necessidade da realização de estudos de época de semeadura. Através desses estudos poderão ser definidas as melhores épocas de cultivo do milheto, onde as necessidades ecofisiológicas da planta sejam preenchidas, visando sua utilização como forrageira ou cobertura vegetal do solo e/ou para produção de grãos ou sementes.

Sabe-se que para a eficiente germinação das sementes é necessário que a temperatura média do solo seja superior a $20^{\circ} \mathrm{C}$, além de haver umidade suficiente para satisfatória emergência das plântulas (Salton e Kichel,1997). Nas condições do sistema de plantio direto, a ocorrência de precipitações entre 30 e 40mm viabiliza boa formação da lavoura. Salton e Kichel (1997) recomendam a semeadura do milheto no oeste do estado de São Paulo, Triângulo Mineiro, sul de Goiás, sul de Mato Grosso e centro-norte de Mato Grosso de Sul no outono, logo após a colheita da safra de verão, visando o aproveitamento das últimas chuvas e, conseqüentemente, melhor estabelecimento da cultura. No sul de Mato Grosso do Sul e no Paraná, a recomendação é para a primavera.

O milheto é uma espécie classificada como de dias curtos, quanto às necessidades fotoperiódicas, apesar de existirem populações de dias neutros (Burton, 1972; Burger, 1984). A manipulação do fotoperíodo e da temperatura pode induzir a antese prematura (Hellmers e Burton, 1972).

Ao visar-se a dupla utilização do milheto, ou seja, para produção de forragem e de semente, Scheffer et al. (1985) recomendam sua semeadura em linhas espaçadas de $0,50 \mathrm{~m}$, aplicação parcelada de $200 \mathrm{~kg} \cdot \mathrm{ha}^{-1}$ de $\mathrm{N}$ e a realização de dois cortes ou pastejo das plantas em estádio vegetativo até o final de dezembro. A pastagem deve ser diferida (vedada) para possibilitar a colheita das sementes posteriormente.

Estudando no milheto, cv. Comum do RS, os efeitos de sistemas de corte da forragem e épocas de colheita sobre a produção e qualidade de sementes de milheto Monks e Peske (1997), constataram que com a realização de dois cortes de forragem foi possível produzir ao redor de 6,5 th.ha $^{-1}$ de matéria seca, sem acarretar prejuízos na produção e qualidade das sementes. Verificaram ainda que o resíduo da cultura de milheto para produção de sementes, com até um corte prévio para forragem, apresentou produção em torno de 11 t.ha ${ }^{-1}$ de matéria seca. Por sua vez, Scheffer et al. (1985) concluíram que o aumento da freqüência de cortes reduziu o rendimento das sementes, mas não afetou sua germinação e vigor.

Estes resultados apontam para uma boa possibilidade de aliar-se produção de sementes à produção de fitomassa de milheto com regimes de corte, visando a utilização como forragem ou para aumento da fitomassa.

O objetivo do presente trabalho foi estudar o comportamento do milheto em condições de Botucatu, após diferentes regimes de corte, semeado em duas épocas, visando a produção de sementes, para verificar a possibilidade de utilização em sucessão/rotação com culturas de verão.

\section{MATERIAL E MÉTODOS}

O experimento foi realizado na área do Departamento de Produção Vegetal - Agricultura, da Faculdade de Ciências 
Agronômicas, Campus de Botucatu, Uiversidade Estadual Paulista (UNESP), localizada no município de Botucatu - SP, definida pelas coordenadas geográficas: $815 \mathrm{~m}$ de altitude, $22^{\circ} 50^{\prime} 59^{\prime \prime}$ 'S e $48^{\circ} 25^{\prime} 54^{\prime \prime}$ O. Foi conduzido em condições de túnel plástico de 5,20 (largura) x 20,00 (comprimento) x 2,5m (pé-direito), revestidos nas faces e lateralmente com tela (abertura de malha $4 \mathrm{~mm}^{2}$ ) e cobertura plástica com filme de polietileno transparente com $150 \mu$ de espessura, sem controle ambiental, e com função específica de proteção contra ataque de pássaros (Farinelii et al., 2004) e de controle de irrigação.

Empregaram-se vasos plásticos de $10 \mathrm{~L}$, com $24 \mathrm{~cm}$ de diâmetro. O solo utilizado foi coletado na camada de $0-20 \mathrm{~cm}$ de Nitossolo Vermelho (Oliveira et al, 1999), realizando-se correção prévia de sua fertilidade com $15 \mathrm{~g}$ de calcário dolomítico PRNT 95, visando elevar a saturação por bases do solo para $70 \%$; com $20 \mathrm{~g}$ de superfosfato simples; $2,5 \mathrm{~g}$ de cloreto de potássio e $2,0 \mathrm{~g}$ de sulfato de amônio, antes de colocá-lo nos vasos. As correções foram baseadas nos resultados da análise química do solo que apresentou $\mathrm{pH}$ de 4,$02 ; 19,3 \mathrm{~g} \cdot \mathrm{kg}^{-1}$ de matéria orgânica; $0,2 \mathrm{mg} \cdot \mathrm{dm}^{-3}$ de fósforo; $47,7 \mathrm{mmol}_{\mathrm{c}} \cdot \mathrm{dm}^{-3}$ de hidrogênio mais alumínio; $0,7 \mathrm{mmol}_{\mathrm{c}} \cdot \mathrm{dm}^{-3} \mathrm{de}$ potássio; 7,0 $\mathrm{mmol}_{\mathrm{c}} \cdot \mathrm{dm}^{-3}$ de cálcio; $2,6 \mathrm{mmol}_{\mathrm{c}} \cdot \mathrm{dm}^{-3} \mathrm{de}$ Magnésio; $10,3 \mathrm{mmol}_{\mathrm{c}} \cdot \mathrm{dm}^{-3} \mathrm{de}$ soma de bases; $57,9 \mathrm{mmol}_{\mathrm{c}} \cdot \mathrm{dm}^{-3} \mathrm{de}$ capacidade de troca catiônica e saturação por bases de $18 \%$.

O delineamento experimental empregado foi blocos casualizados, com duas épocas de semeadura (abril e setembro de 2000), cada uma com cinco tratamentos: $\mathrm{T}_{1}$ ) crescimento livre, sem cortes; $\mathrm{T}_{2}$ ) um corte quando a planta atingiu 50 a $70 \mathrm{~cm}$ de altura; $\mathrm{T}_{3}$ ) um corte quando a planta atingiu o florescimento; $\mathrm{T}_{4}$ ) seqüência de três cortes quando a planta atingiu 50 a $70 \mathrm{~cm}$ de altura; $\mathrm{T}_{5}$ ) seqüência de dois cortes quando a planta atingiu o florescimento. Cada tratamento com cinco repetições, representadas por cada vaso. A cultivar empregada foi a BN2, variedade sintética desenvolvida a partir de introduções de milheto proveniente da África, sendo utilizada para forragem e para cobertura do solo (Netto et al., 1997).

A semeadura foi realizada com número maior de sementes (30), para realizar-se o desbaste aos 30 dias após a emergência das plântulas, deixando as três plantas mais vigorosas do vaso. Foram realizadas irrigações diárias, conforme a necessidade, adubações em cobertura com nitrogênio ( $2 \mathrm{~g}$ de sulfato de amônio por vaso) a cada 15 dias e o controle de pragas e doenças, quando necessário.

O desenvolvimento das plantas foi acompanhado através de avaliações dos estádios fenológicos, descritos em ICRISAT (1977), para a realização dos cortes.
Os cortes foram realizados à altura de $10-15 \mathrm{~cm}$ do solo (Scheffer et al., 1985) quando as plantas do vaso atingiram a condição descrita nos tratamentos. Após o último corte, as plantas foram deixadas em crescimento livre, à semelhança do tratamento $T_{1}$, até a produção de sementes ou maturação total da planta (quando da não produção de sementes).

Finalizado o ciclo da cultura, quando as plantas atingiram a senescência, em média 130 dias após a semeadura para abril e 140 dias para setembro, avaliou-se o número de perfílhos, o número de perfílhos com panícula, o número e o peso de sementes por panícula. Com estes dados, foram calculados a porcentagem de perfílhos úteis, o número total de sementes por planta e a produção de sementes por planta.

Em laboratório foram feitas as seguintes avaliações: (a) massa de mil sementes (Brasil, 1992); (b) teor de água das sementes pelo método da estufa a $105 \pm 3^{\circ} \mathrm{C}$ por 24 horas (Brasil, 1992); (c) germinação, utilizando-se temperaturas alternadas de $20-30^{\circ} \mathrm{C}$, com 4 subamostras de 100 sementes (Brasil, 1992) e (d) vigor, por meio da primeira contagem do teste de germinação, condutividade elétrica e emergência em solo. As sementes dormentes computadas ao final do teste de germinação foram aquelas que permaneceram duras, ou seja, não embeberam durante o teste. Os dados de condutividade elétrica foram obtidos pelo método de massa, com duas subamostras de 50 sementes por repetição que, após pesadas, foram colocadas em copos plásticos contendo $75 \mathrm{~mL}$ de água destilada e mantidas por $24 \mathrm{~h}$ em câmara a $25^{\circ} \mathrm{C}$; após esse período foi feita a leitura em condutivímetro e os valores obtidos foram calculados em $\mu \mathrm{S} . \mathrm{cm}^{-1} . \mathrm{g}^{-1}$ (Vieira e Carvalho, 1994). A emergência de plântulas foi determinada em bandejas plásticas de 41×26x8cm com capacidade aproximada de 8,5L de solo, onde foram semeadas 4 subamostras de 100 sementes; as bandejas foram colocadas sob túnel plástico, com irrigações conforme necessário e realizando-se contagens diárias das plântulas emergidas até que este número se estabilizasse.

As avaliações de teor de água e qualidade fisiológica foram realizadas novamente após as sementes, embaladas em sacos de papel, permanecerem por 24 meses armazenadas em laboratório sob condições não controladas de temperatura e umidade relativa.

As sementes do tratamento T1 da semeadura de abril foram selecionadas para realização dos testes, eliminando-se as perfuradas, pois estas sofreram ataques de carunchos durante o armazenamento. Como as avaliações foram realizadas em períodos distintos para cada época de semeadura, a fim de se obter os 24 meses de armazenamento, 
os dados referentes à emergência de plântulas não foram comparados entre épocas, pois as condições ambientais dos testes foram diferentes.

Os dados em porcentagem e contagens (em número) que apresentaram valores nulos foram transformados em ( $\mathrm{x}$ $+0,5)^{1 / 2}$ e os de contagens sem valores nulos, transformados em $(\mathrm{x})^{1 / 2}$ para, a seguir, serem submetidos à análise estatística (Gomes, 2000; Barbin, 2003) através da análise conjunta das épocas de semeadura. Os demais dados foram analisados sem transformação. As médias foram comparadas pelo teste de Tukey a 5\% de significância.

\section{RESULTADOS E DISCUSSÃO}

Os resultados obtidos permitem observar os efeitos da época de semeadura e do regime de corte na produção e qualidade das sementes de milheto (Tabelas 1, 2 e 3).

Para a semeadura de abril, o aumento do número de cortes aumentou o número de perfílhos em relação à testemunha (T1), independente do estádio vegetativo em que se encontravam as plantas (Tabelas 1), enquanto que na de setembro, este número não foi afetado pelos tratamentos. $\mathrm{Na}$ comparação entre as épocas, abril superou setembro, quanto ao número de perfílhos na maioria dos tratamentos estudados
(Tabela 1), por provável influência do fotoperíodo, por ser o milheto uma planta de dias curtos (Burger, 1984) e da energia ambiental e calor (Ferraris e Norman, 1976).

O número de perfílhos com panícula, quando comparado à testemunha (T1), não apresentou diferença significativa, embora os mais expressivos valores tenham sido obtidos nos tratamentos com maior número de cortes e cortes no florescimento (T3, T4 e T5), para a semeadura de abril; já na semeadura de setembro, não houve diferença significativa entre os tratamentos. Entre as épocas de semeadura, abril superou setembro em todos os tratamentos estudados (Tabela $1)$.

A porcentagem de perfílhos úteis não diferiu entre os tratamentos para semeadura de abril; na semeadura de setembro, foi maior para o T4, embora não tenha diferido de T1, T2 e T3. Entre as épocas, abril superou setembro apenas para T2 (Tabela 1). A porcentagem de perfílhos úteis se relacionou com o número total de perfílhos e com o número de perfílhos com panícula, para a semeadura de abril, permitindo afirmar que a emissão do perfilho implicou na formação de panícula; já na semeadura de setembro, essa relação não foi observada, predominando os perfílhos vegetativos, isto é, sem panícula. O efeito dos cortes sobre a emissão de perfílhos também foi evidente na semeadura de abril.

TABELA1. Dados médios do número de perfilhos por planta, número de perfilhos com panícula, porcentagem de perfilhos úteis (com panícula), número de sementes por planta, número de sementes por panícula e produção de sementes obtidas em função dos cortes (T1, T2, T3, T4 e T5) e épocas de semeadura (abril e setembro) de milheto. Botucatu 2001.

\begin{tabular}{|c|c|c|c|c|c|c|}
\hline \multirow[t]{2}{*}{ Tratamento } & \multicolumn{2}{|c|}{$\begin{array}{l}\text { Perfilhos.Planta } \\
\qquad\left(n^{\circ}\right)\end{array}$} & \multicolumn{2}{|c|}{$\begin{array}{c}\text { Perfilhos com Panícula } \\
\left(\mathrm{n}^{\circ}\right)\end{array}$} & \multicolumn{2}{|c|}{$\begin{array}{c}\text { Perfilhos Úteis } \\
(\%)\end{array}$} \\
\hline & Abril & Setembro & Abril & Setembro & Abril & Setembro \\
\hline $\mathrm{T} 1$ & $7,1 \mathrm{BCa}^{1}$ & $2,5 \mathrm{Ab}$ & $3,6 \mathrm{ABa}$ & $0,7 \mathrm{Ab}$ & $55,3 \mathrm{Aa}$ & $34,6 \mathrm{ABa}$ \\
\hline $\mathrm{T} 2$ & $4,7 \mathrm{Ca}$ & $2,7 \mathrm{Aa}$ & $2,8 \mathrm{Ba}$ & $0,6 \mathrm{Ab}$ & $61,4 \mathrm{Aa}$ & $23,1 \mathrm{ABb}$ \\
\hline $\mathrm{T} 3$ & 7,5 $\mathrm{ABCa}$ & $3,7 \mathrm{Ab}$ & $4,3 \mathrm{Aa}$ & $1,4 \mathrm{Ab}$ & $56,4 \mathrm{Aa}$ & $40,5 \mathrm{ABa}$ \\
\hline $\mathrm{T} 4$ & $10,6 \mathrm{Aa}$ & $2,7 \mathrm{Ab}$ & $4,8 \mathrm{Aa}$ & $1,4 \mathrm{Ab}$ & $45,9 \mathrm{Aa}$ & $51,2 \mathrm{Aa}$ \\
\hline $\mathrm{T} 5$ & $10,1 \mathrm{ABa}$ & $4,3 \mathrm{Ab}$ & $4,2 \mathrm{ABa}$ & $0,8 \mathrm{Ab}$ & $41,7 \mathrm{Aa}$ & $18,0 \mathrm{Ba}$ \\
\hline C.V. $(\%)$ & \multicolumn{2}{|c|}{11,67} & \multicolumn{2}{|c|}{12,60} & \multicolumn{2}{|c|}{33,69} \\
\hline \multicolumn{7}{|l|}{ Continuação. } \\
\hline \multirow[t]{2}{*}{ Tratamento } & \multicolumn{2}{|c|}{$\begin{array}{l}\text { Sementes.Planta }{ }^{-1} \\
\left(\mathrm{n}^{\circ}\right)\end{array}$} & \multicolumn{2}{|c|}{$\begin{array}{l}\text { Sementes.Panícula }{ }^{-1} \\
\left(\mathrm{n}^{\circ}\right)\end{array}$} & \multicolumn{2}{|c|}{$\begin{array}{l}\text { Produção de Sementes } \\
\left(\text { g.planta }{ }^{-1}\right)\end{array}$} \\
\hline & Abril & Setembro & Abril & Setembro & Abril & Setembro \\
\hline $\mathrm{T} 1$ & $1321 \mathrm{Aa}$ & $1893 \mathrm{Aa}$ & $113 \mathrm{Ab}$ & $1776 \mathrm{Aa}$ & $5,1 \mathrm{Aa}^{1}$ & $5,4 \mathrm{~A} \mathrm{a}$ \\
\hline $\mathrm{T} 2$ & $930 \mathrm{Aa}$ & $1238 \mathrm{ABa}$ & $91 \mathrm{Ab}$ & $1254 \mathrm{Aa}$ & $3,6 \mathrm{ABa}$ & $4,6 \mathrm{~A} \mathrm{a}$ \\
\hline T3 & $962 \mathrm{Aa}$ & $171 \mathrm{Cb}$ & $114 \mathrm{Aa}$ & $155 \mathrm{Ba}$ & 2,9 $\mathrm{ABCa}$ & $0,7 \mathrm{~B}$ a \\
\hline $\mathrm{T} 4$ & $244 \mathrm{Ba}$ & $523 \mathrm{BCa}$ & $32 \mathrm{Ab}$ & $400 \mathrm{Ba}$ & $0,5 \mathrm{Ca}$ & $1,3 \mathrm{~B} \mathrm{a}$ \\
\hline T5 & $564 \mathrm{ABa}$ & $128 \mathrm{Cb}$ & $68 \mathrm{Aa}$ & $161 \mathrm{Ba}$ & $1,0 \mathrm{BCa}$ & $0,3 \mathrm{~B} \mathrm{a}$ \\
\hline C.V. (\%) & \multicolumn{2}{|c|}{24,43} & \multicolumn{2}{|c|}{38,36} & \multicolumn{2}{|c|}{49,72} \\
\hline
\end{tabular}

${ }^{1}$ Letra maiúscula comparação na coluna, letra minúscula comparação na linha. Médias seguidas da mesma letra não diferem entre si significativamente a $5 \%$ de probabilidade pelo teste Tukey 
TABELA 2. Dados médios de teor de água das sementes, sementes mortas, primeira contagem de germinação, emergência de plântulas, massa de 1000 sementes, germinação, sementes dormentes, plântulas anormais e condutividade elétrica obtidos em função dos cortes (T1, T2, T3, T4 e T5) e época de semeadura (abril e setembro) de milheto. Botucatu, 2001

\begin{tabular}{|c|c|c|c|c|c|c|c|c|}
\hline \multirow[t]{2}{*}{ Tratamento } & \multicolumn{2}{|c|}{ Teor de Água (\%) } & \multicolumn{2}{|c|}{ Sementes Mortas (\%) } & \multicolumn{2}{|c|}{$1^{\mathrm{a}}$ Contagem $(\%)$} & \multicolumn{2}{|c|}{ Emergência de Plântulas (\%) } \\
\hline & Abril & Setembro & Abril & Setembro & Abril & Setembro & Abril & Setembro \\
\hline $\mathrm{T} 1$ & $10,5 \mathrm{~A} \mathrm{a}$ & $10,9 \mathrm{C} \mathrm{a}$ & $4 \mathrm{AB} a$ & $4 \mathrm{~A} \mathrm{a}$ & $84 \mathrm{~A} \mathrm{a}$ & $13 \mathrm{AB} \mathrm{b}$ & $87 \mathrm{~A} \mathrm{a}$ & $50 \mathrm{~B} \mathrm{~b}$ \\
\hline $\mathrm{T} 2$ & $10,3 \mathrm{~A} \mathrm{a}$ & $10,8 \mathrm{C} \mathrm{a}$ & $2 \mathrm{~B}$ a & $4 \mathrm{~A} \mathrm{a}$ & $88 \mathrm{~A} \mathrm{a}$ & $20 \mathrm{AB} \mathrm{b}$ & $88 \mathrm{~A} \mathrm{a}$ & $57 \mathrm{~B} \mathrm{~b}$ \\
\hline $\mathrm{T} 3$ & $10,4 \mathrm{~A} \mathrm{~b}$ & $12,3 \mathrm{~A} \mathrm{a}$ & $4 \mathrm{~B} \mathrm{a}$ & $3 \mathrm{~A} \mathrm{a}$ & $59 \mathrm{~A} \mathrm{a}$ & $42 \mathrm{~A} \mathrm{a}$ & $85 \mathrm{~A} \mathrm{a}$ & $52 \mathrm{~B} \mathrm{~b}$ \\
\hline $\mathrm{T} 4$ & $10,8 \mathrm{~A} \mathrm{a}$ & $11,2 \mathrm{BC}$ a & $12 \mathrm{~A} \mathrm{a}$ & $3 \mathrm{Ab}$ & $59 \mathrm{~A} \mathrm{a}$ & $6 \mathrm{~B} \mathrm{~b}$ & $73 \mathrm{~A} \mathrm{a}$ & $46 \mathrm{~B} \mathrm{~b}$ \\
\hline T5 & $9,7 \mathrm{Ab}$ & $13,5 \mathrm{~A} \mathrm{a}$ & $5 \mathrm{AB}$ a & $6 \mathrm{~A} \mathrm{a}$ & $70 \mathrm{~A} \mathrm{a}$ & $39 \mathrm{~A} \mathrm{a}$ & $82 \mathrm{~A} \mathrm{a}$ & $84 \mathrm{~A} \mathrm{a}$ \\
\hline C.V. $(\%)$ & \multicolumn{2}{|c|}{5,77} & \multicolumn{2}{|c|}{41,29} & \multicolumn{2}{|c|}{20,28} & \multicolumn{2}{|c|}{16,39} \\
\hline \multicolumn{9}{|c|}{... Continuação. } \\
\hline Tratamento & \multicolumn{2}{|c|}{$\begin{array}{c}\text { Massa de } 1000 \\
(\mathrm{~g})\end{array}$} & $\begin{array}{l}\text { inação } \\
\text { o) }\end{array}$ & \multicolumn{2}{|c|}{$\begin{array}{l}\text { Sementes Dormentes } \\
(\%)\end{array}$} & $\begin{array}{c}\text { Plântulas Anormais } \\
(\%)\end{array}$ & \multicolumn{2}{|c|}{$\begin{array}{c}\text { Condutividade Elétrica } \\
\left(\mu \mathrm{S} \cdot \mathrm{cm}^{-1} \cdot \mathrm{g}^{-1}\right)\end{array}$} \\
\hline $\mathrm{T} 1$ & \multicolumn{2}{|c|}{$3,32 \mathrm{AB}$} & $9 \mathrm{~A}$ & \multicolumn{2}{|c|}{$14 \mathrm{~A}$} & $3 \mathrm{~A}$ & \multicolumn{2}{|c|}{$103,6 \mathrm{~B}$} \\
\hline $\mathrm{T} 2$ & \multicolumn{2}{|c|}{$4,06 \mathrm{~A}$} & $2 \mathrm{~A}$ & \multicolumn{2}{|c|}{$11 \mathrm{~A}$} & $3 \mathrm{~A}$ & \multicolumn{2}{|c|}{$97,6 \mathrm{~B}$} \\
\hline $\mathrm{T} 3$ & \multicolumn{2}{|c|}{$3,23 \mathrm{AB}$} & $1 \mathrm{~A}$ & \multicolumn{2}{|c|}{$10 \mathrm{~A}$} & $6 \mathrm{~A}$ & \multicolumn{2}{|c|}{$86,5 \mathrm{~B}$} \\
\hline $\mathrm{T} 4$ & \multicolumn{2}{|c|}{$2,17 \mathrm{~B}$} & $7 \mathrm{~A}$ & \multicolumn{2}{|c|}{$23 \mathrm{~A}$} & $3 \mathrm{~A}$ & \multicolumn{2}{|c|}{$169,9 \mathrm{~A}$} \\
\hline T5 & \multicolumn{2}{|c|}{$1,93 \mathrm{~B}$} & $1 \mathrm{~A}$ & \multicolumn{2}{|c|}{$5 \mathrm{~A}$} & $8 \mathrm{~A}$ & \multicolumn{2}{|c|}{$123,2 \mathrm{AB}$} \\
\hline Abril & \multicolumn{2}{|c|}{$2,97 \mathrm{a}$} & $0 \mathrm{a}$ & \multicolumn{2}{|c|}{$4 \mathrm{~b}$} & $2 \mathrm{a}$ & \multicolumn{2}{|c|}{109,9 a } \\
\hline Setembro & \multicolumn{2}{|c|}{$2,92 \mathrm{a}$} & $8 \mathrm{~b}$ & \multicolumn{2}{|c|}{$22 \mathrm{a}$} & $2 \mathrm{a}$ & \multicolumn{2}{|c|}{$122,4 \mathrm{a}$} \\
\hline C.V. $(\%)$ & 39,42 & & 7,91 & & & 33,53 & & \\
\hline
\end{tabular}

${ }^{1}$ Letra maiúscula comparação na coluna, letra minúscula comparação na linha. Médias seguidas da mesma letra não diferem entre si significativamente ao nível de $5 \%$ de probabilidade, pelo teste Tukey.

TABELA3. Dados médios de teor de água das sementes, germinação, sementes mortas, primeira contagem de germinação, emergência de plântulas, sementes dormentes, plântulas anormais e condutividade elétrica obtidos após o armazenamento em função dos cortes (T1, T2, T3, T4 e T5) e época de semeadura (abril e setembro) de milheto. Botucatu, 2001.

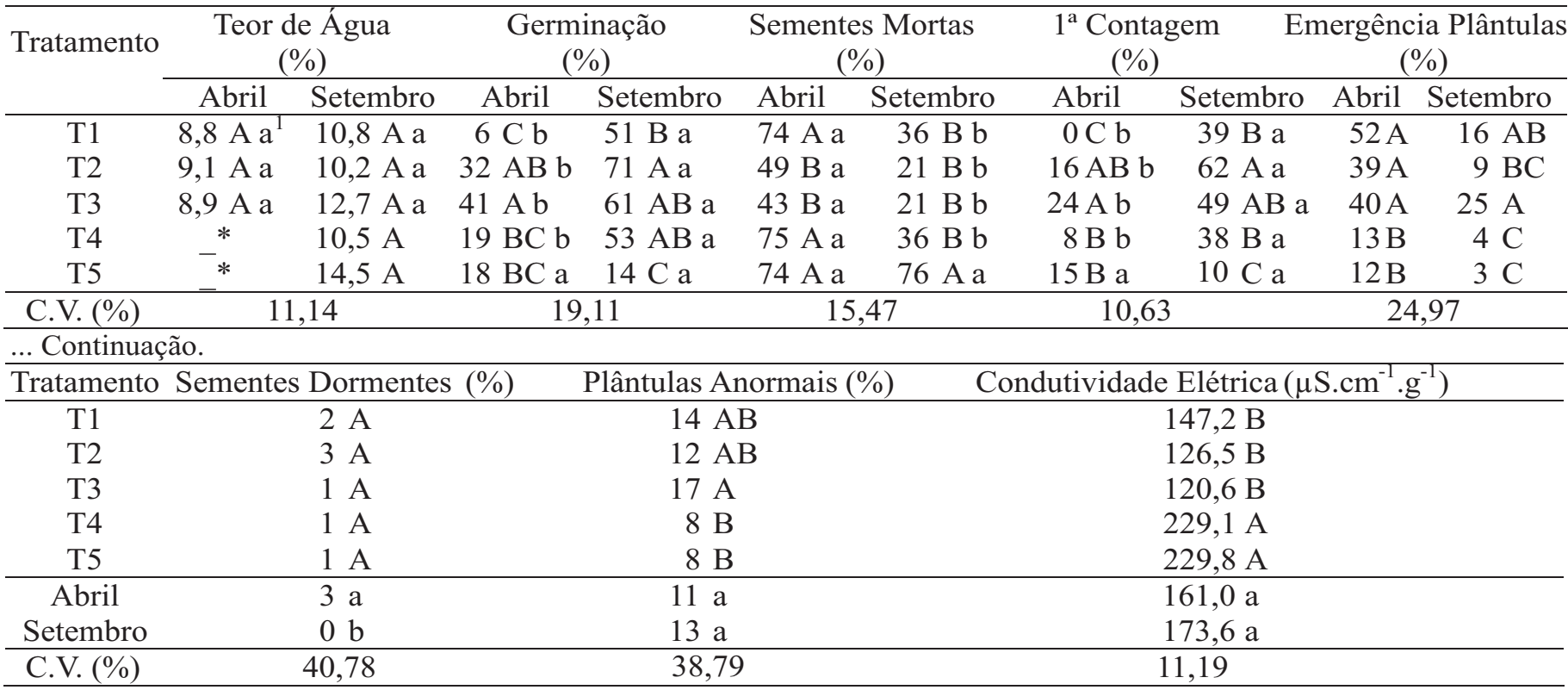

*Dados não analisados. ${ }^{1}$ Letra maiúscula comparação na coluna, letra minúscula comparação na linha. Médias seguidas da mesma letra não diferem entre si significativamente a $5 \%$ de probabilidade, pelo teste Tukey.

Para a semeadura de abril, o número de sementes por planta diminuiu em função do número de cortes, independente do estádio fenológico da planta; já na semeadura de setembro, os cortes realizados no florescimento não foram favoráveis à produção de sementes (T3 e T5) (Tabela 1). Entre as épocas de semeadura, abril superou estatisticamente setembro quanto ao número de sementes por planta nos tratamentos T3 e T5, mostrando que para esta época de semeadura o corte realizado 
na fase reprodutiva, independente da quantidade, desfavorece a produção de sementes em número (Tabela 1). As mesmas tendências foram observadas para o número de sementes por panícula e produção de sementes em peso (Tabela 1). Os melhores resultados para estas características foram obtidos nos tratamentos T1 e T2, mostrando que um corte no estádio vegetativo (T2) foi semelhante à testemunha (T1) (Tabela 1).

As produções de sementes de $\mathrm{T} 1$ e $\mathrm{T} 2$ respectivamente 5,1 e 3,6g.planta ${ }^{-1}$, para semeadura de abril e 5,4 e 4,6g.planta ${ }^{-1}$, para semeadura de setembro, são próximas àquelas obtidas por Geraldo et al. (2000), podendo assim serem consideradas elevadas. Segundo Squire et al. (1984), rendimentos elevados podem ser atribuídos à boa disponibilidade hídrica no cultivo (média $853 \mathrm{~mm}$ ), associada às temperaturas adequadas (média de $25,3^{\circ} \mathrm{C}$ ), dentro da faixa ótima de 25 a $27^{\circ} \mathrm{C}$ para a máxima taxa de crescimento do milheto. Já os tratamentos com cortes no florescimento (T3 e T5) e maior número de cortes (T4 e T5), à semelhança de Scheffer et al. (1985), não foram favoráveis à produção de sementes.

O teor de água das sementes após a colheita manteve-se praticamente constante, próximo aos $10 \%$, entre os tratamentos da semeadura de abril, sem apresentar diferenças significativas; na semeadura de setembro, os tratamentos T3 e T5 apresentaram teor de água mais elevado 12,3 e 13,5\%, respectivamente (Tabela 2), porém estas diferenças entre os tratamentos podem não ter interferido nas demais avaliações.

Para a massa de mil sementes não houve efeito de interação entre épocas e tratamentos, com diferenças significativas apenas entre os tratamentos (Tabela 2). Comparada à testemunha, a massa de mil sementes foi maior para os tratamentos que sofreram apenas um corte (T2 e T3), demonstrando assim que o aumento do número de cortes desfavorece o ganho de massa das sementes produzidas (Tabela 2), resultados semelhantes foram obtidos por Monks e Ferreira (2004).

Para a germinação não houve efeito de interação entre épocas e tratamentos, havendo diferença significativa somente entre épocas, com as sementes produzidas em abril apresentando maior germinação do que aquelas produzidas em setembro (Tabela 2).

A porcentagem de plântulas anormais não foi afetada pela época de semeadura, pelos tratamentos ou pela interação entre esses fatores (Tabela 2).

A porcentagem de sementes mortas, para a semeadura de abril, foi maior no T4 (12\%), como provável conseqüência do maior número de cortes sofridos pelas plantas; para setembro, não houve diferença entre os tratamentos. Entre as épocas, somente no T4 abril superou setembro (Tabela 2).

Quanto às sementes dormentes não houve efeito de interação entre épocas e tratamentos, havendo diferença significativas apenas entre épocas, onde setembro superou abril em seis vezes quanto à porcentagem de sementes dormentes (Tabela 2). Esses resultados permitem observar a presença de dormência em sementes de milheto (cultivar BN2) recém colhidas, não havendo influência dos tratamentos adotados.

Com relação à primeira contagem do teste de germinação, na semeadura de abril, não houve diferença entre os tratamentos; já em setembro, destacaram-se os tratamentos T3 e T5, ou seja, aqueles que sofreram cortes no florescimento, seguidos de T1 e T2, com vigor intermediário e T4 com baixo vigor. Entre as épocas de semeadura, abril superou setembro na maioria dos tratamentos estudados, com exceção de T3 e T5 (Tabela 2), todavia a presença de sementes dormentes pode ter interferido nos resultados deste teste como parâmetro de vigor. Quanto ao teste de condutividade elétrica, não houve efeito de interação entre épocas e tratamentos, havendo diferença significativa apenas entre tratamentos. Comparados à testemunha (T1), destacaram-se os tratamentos T3 e T2 (Tabela 2).

A emergência de plântulas não diferiu entre os tratamentos para a semeadura de abril; já para a semeadura de setembro houve diferença significativa entre os tratamentos, com destaque para T5 com $84 \%$ de plântulas emergidas. Entre as épocas de semeadura, com exceção de T5, abril superou setembro em todos os tratamentos (Tabela 2), acompanhando os resultados de germinação em laboratório.

O teor de água das sementes após o armazenamento (Tabela 3) foi maior para os tratamentos T1, T2 e T3 na semeadura de abril e seus valores não acompanharam as variações do teor de água antes do armazenamento; já em setembro, não houve variação entre os tratamentos e os valores mantiveram as variações da primeira avaliação, antes do armazenamento.

A germinação após o armazenamento sofreu efeito de interação entre épocas e tratamentos, o que não havia ocorrido na avaliação após a colheita. Entre as épocas, setembro superou abril para a maioria dos tratamentos, destacando-se o tratamento T2 com maior porcentagem de germinação, embora não tenha diferido de T3 e T4, fator esse explicado pelo menor número de sementes dormentes após o armazenamento (Tabela 3).

A porcentagem de sementes mortas após o armazenamento, para a semeadura de abril, foi maior nos 
tratamentos T1 (devido ao ataque de carunchos), T3 e T5 e para setembro, no T5, justificando assim a baixa germinação apresentada por esses tratamentos. Entre as épocas, abril superou setembro para a maioria dos tratamentos, exceto no T5 (Tabela 3).

A porcentagem de plântulas anormais após o armazenamento não apresentou diferença entre as épocas, o que não ocorreu na primeira avaliação; entre os tratamentos, destacaram-se T4 e T5 com menor porcentagem de plântulas anormais (Tabela 3).

Pelos testes de vigor empregados após o armazenamento, na semeadura de abril, na primeira contagem do teste de germinação destacou-se o tratamento T3 e em setembro, destacou-se T2, ambos com maior porcentagem de plantulas normais. Entre as épocas de semeadura, abril superou setembro na maioria dos tratamentos estudados (Tabela 3).

Quanto à condutividade elétrica, não houve efeito de interação entre épocas e tratamentos, havendo diferença significativa apenas entre tratamentos, à semelhança da avaliação após a colheita. Comparados à testemunha (T1), apresentaram maior vigor os tratamentos T3 e T2, seguidos de T4 e T5, com baixo vigor (Tabela 3).

$\mathrm{O}$ vigor, avaliado pela emergência de plântulas após o armazenamento, mostrou que para a semeadura de abril, o manejo de cortes não foi favorável à emergência, principalmente com o aumento do número de cortes (T4 e T5); a mesma tendência foi observada na semeadura de setembro (Tabela 2).

\section{CONCLUSÕES}

Sementes de milheto produzidas em abril apresentam melhor qualidade do que as produzidas em setembro.

$\mathrm{O}$ aumento da freqüência de cortes reduz a produção e afeta a qualidade das sementes de milheto para as semeaduras em abril e setembro.

Após o armazenamento, o vigor e a germinação das sementes diminui, para a maioria dos tratamentos, em ambas as épocas de semeadura.

Após o armazenamento, as sementes obtidas na semeadura de setembro apresentam os melhores resultados de vigor e germinação, na comparação entre as épocas.

A semeadura em abril, com no máximo um corte na fase vegetativa, mostra-se a melhor combinação para a produção de sementes de milheto em Botucatu.

\section{AGRADECIMENTOS}

À FAPESP, pela bolsa de iniciação científica concedida ao primeiro autor para o desenvolvimento deste trabalho científico, durante a graduação.

\section{REFERÊNCIAS}

ALCÂNTARA, P.B.; BUFARAH, G. Plantas forrageiras: gramíneas e leguminosas. 4 ed. São Paulo: Nobel, 1988. 162p.

BARBIN, D. Planejamento e análise de experimentos agronômicos. Arapongas: Midas, 2003. 208p.

BRASIL. Ministério da Agricultura e Reforma Agrária. Regras para análise de sementes. Brasília: SNDA/DNDV/CLAV, 1992. 365p.

BURGER, A. W. Crop classification. In: TESAR, M. B. (Ed.). Physiological bases of crop growth and development. Madison: American Society of Agronomy, 1984. p.01-12.

BURTON, G. W. Registration of Tiflate pearl millet. Crop Science, Madison, v.12, n.1, p.128, 1972.

FARINELLI, R.; LEMOS, L. B.; PENARIOL, F. G.; NASCIMENTO, S. Desempenho da cultura do milheto em função de épocas de semeadura e do manejo de corte da parte aérea. Revista Brasileira de Milho e Sorgo, Sete Lagoas, v.3, n.3, p.391-401, 2004.

FERRARIS, R.; NORMAN, M. J.T. Factors affecting the regrowth of Pennisetum americanum _ under frequent defoliation. Australian Journal of Agricultural Research, East Melbourne, v.27, p.365-71, 1976.

GERALDO, J.; ROSSIELLO, R. O. P.; ARAÚJO, A. P.; PIMENTEL, C. Diferenças em crescimento e produção de grãos entre quatro cultivares de milheto pérola. Pesquisa Agropecuária Brasileira, Brasília, v. 35, n.7, p.1367-1376, 2000.

GOMES, F.P. Curso de estatística experimental. $14^{\mathrm{a}}$ ed. Piracicaba: ESALQ, 2000. 477p.

GUIDELLI, C.; FAVORETTO, V.; MALHEIROS, E.B. Produção e qualidade do milheto semeado em duas épocas e adubado com nitrogênio. Pesquisa Agropecuária Brasileira, Brasília, v.35, n.10, p.2093-2098, 2000.

HELLMERS, H.; BURTON, G.W. Photoperiod and temperature manipulation indices early anthesis in pearl millet. Crop Science, Madison, v.12, n.2, p.198-200, 1972.

ICRISAT. Pearl millet. In: ICRISAT Anual Report 1976-1977. Hyderabad: ICRISAT, 1977. p.47-71.

LEMOS, L.B.; NAKAGAWA, J.; CRUSCIOL, C.A.; CHINGNOLIJÚNIOR, W.; SILVA, T.R.B. Influência da época de semeadura e do manejo da parte aérea de milheto sobre a soja em sucessão em plantio direto. Bragantia, Campinas, v.62, n.3, p.405-415, 2003.

MONKS, P.L.; PESKE, S.T. Produção e qualidade de sementes de milheto (Pennisetum glaucum (L.) R. Br.) submetido a manejo de cortes e a épocas de colheita. In: CONGRESSO BRASILEIRO DE SEMENTES, 10., 1997, Foz do Iguaçu. Informativo ABRATES, Londrina, v.7, n.1/2, p.246, 1997. 
MONKS, P.L.; FERREIRA, O.G.L. Manejo de cortes e épocas de colheita de sementes de milheto (Pennisetum americanum) - II. Vigor das sementes. In: REUNIÓN DEL GRUPO TÉCNICO REGIONAL DEL CONO SUR EN MEJORAMIENTO Y UTILIZACIÓN DE LOS RECURSOS FORRAJEROS DEL ÁREA TROPICAL Y SUBTROPICAL - SUSTENTABILIDAD, DESARROLLO Y CONSERVACIÓN DE LOS ECOSISTEMAS, 20., Salto, 2004. Anais eletrônicos... Salto: INTA, 2004. Disponível em: <http://www.inta.gov.ar/mercedes/grupocampos/XX/ 2\%20SEMILLAS.pdf>. Acesso em 19 mai. 2006.

NETTO, D.A.; ANDRADE, R.V.; OLIVEIRA,A.C.; AZEVEDO, J.T., BORBA,C.S.; ANDREOLI, C. Qualidade de sementes de milheto. (Pennisetum glancum (L.) R. Br.) de diferentes procedências. Informativo ABRATES, Londrina, v.7, n.3, p.48-53, 1997.

OLIVEIRA, J.B.; CAMARGO, M.N.; ROSSI, M.; CALDERON FILHO, B. Mapa pedológico do Estado de São Paulo: legenda expandida. Campinas: Instituto Agronômico; Rio de Janeiro: EMBRAPA-Solos, 1999. 64p.: mapa.

PEREIRA, F.A.R. Cultivo de espécies visando a obtenção de cobertura vegetal do solo na entresafra da soja (Glycine max) (L.) Merril) no cerrado. 1990. 83f. Dissertação (Mestrado em Agronomia-Área de concentração Agricultura)-Faculdade de Ciências Agronômicas, Universidade Estadual Paulista, Botucatu, 1990.
SALTON, J.C. Opções de safrinha para agregação de renda nos cerrados. In: ENCONTRO REGIONAL DE PLANTIO DIRETO NO CERRADO, 4., 2001, Uberlândia. Plantio direto na integração lavoura-pecuária. LARA CABEZAS, W.A.R.; FREITAS, P. L (Ed.). Uberlândia: Universidade Federal de Uberlândia, 2001, p.189-200.

SALTON, J.C.; KICHEL, A.N. Milheto - Alternativa para cobertura do solo e alimentação animal. Dourados: EMBRAPA, 1997. 6p. Folheto.

SCHEFFER, S.M.; SAIBRO, J.C.; RIBOLDI, J. Efeito do nitrogênio, métodos de semeadura e regimes de corte no rendimento e qualidade da forragem e da semente de milheto. Pesquisa Agropecuária Brasileira, Brasília, v.20, n.3, p.309-317, 1985.

SILVA, R.H. Crescimento radicular e nutrição de soja (Glycine max) em função da cultura anterior e da compactação em Latossolo Vermelho-escuro. 1998. 81f. Dissertação (Mestrado em Agronomia - Área de concentração Agricultura)-Faculdade de Ciências Agronômicas, Universidade Estadual Paulista, Botucatu, 1998.

SQUIRE, G.R.; MARSHALL, B.; TERRY, A.C.; MONTEITH, J.L. Response to temperature in a stand of pearl millet. VI. Light interception and dry matter production. Journal of Experimental Botany, London, v.35, p.599-610, 1984.

VIEIRA, R.D.; CARVALHO, N.M. Testes de vigor em sementes. Jaboticabal: FUNEP, 1994. 164p. 